\title{
Effects of non-thermal plasma sterilization on volatile components of tomato juice
}

\author{
T. J. $\mathrm{Ma}^{2} \cdot$ W. S. $\operatorname{Lan}^{1}$
}

Received: 9 October 2013/Revised: 3 November 2013/Accepted: 14 March 2015/Published online: 9 April 2015

(C) Islamic Azad University (IAU) 2015

\begin{abstract}
Pasteurization is an important issue to keep from fruit decay due to microbes for fruit preservation. Conventional heat sterilization is based on thermal process. However, the flavor and nutrition components can be changed by heat damage. In this study, an apparatus was designed to produce non-thermal plasma (NTP), which can be applied in fruit sterilization. NTP can be generated through electric discharge in gaseous chamber. A simple NTP reactor may consist of two electrodes with a chamber and connected to a high-voltage power supply. The new technique of NTP was applied to keep fruit fresh. After the tomatoes were treated by NTP, the volatile flavor components were analyzed by GC-MS and were compared to heat treatment and non-treatment. The results showed that the quality of fresh tomato fruit was unaffected by plasma disinfection treatment, and the contents of trans-2-hexenal and n-hexanal were significantly higher than that by heat processes. NTP has less effect on volatile chemical compositions of tomato juice. NTP technology is a promising method for food pasteurization in the future.
\end{abstract}

Keywords Non-thermal plasma · Tomato juice . Sterilization · Volatile component

W. S. Lan

lanwshao@163.com

1 Shenzhen R\&D Key Laboratory of Alien Pest Detection Technology, Animal \& Plant Inspection and Quarantine Technical Center, Shenzhen Entry-Exit Inspection and Quarantine Bureau, 1011 Fuqiang Road, Shenzhen 518045, China

2 College of Food Science and Engineering, Beijing University of Agriculture, Beijing 102206, China

\section{Introduction}

Different fruit and vegetable juices have their own unique smells and the main flavor components including esters, alcohols, aldehydes, acids also as an important evaluation indicator of product quality, and most of them are volatile components (Hayase et al. 1984; Salles et al. 2003; Riu-Aumatella et al. 2004). During the heat processes, it is difficult to avoid destruction of volatile substances, causing the deterioration of flavor (Servili et al. 2000). In recent years, many scholars have studied the non-thermal sterilization technology; Ma Hongbing and others used plasma technology for liquid food sterilization, and they found that this technology enables the total number of bacteria in fresh juice and milk decrease five logarithms (Ma et al. 2002; Lin et al. 2006). Nonthermal plasma (NTP) generated by corona discharge could inactivate E. coli in apple juices; after plasma treatment for $40 \mathrm{~s}$, the number of $E$. coli decreased five logarithms (Deng et al. 2007).After non-thermal plasma for decontamination of $E$. coli in milk, the initial preplasma bacterial count of $7.78 \mathrm{Log} \mathrm{CFU} / \mathrm{mL}$ in whole milk was decreased to $3.63 \mathrm{Log} \mathrm{CFU} / \mathrm{mL}$ after $20 \mathrm{~min}$ of plasma application. Non-thermal plasma did not cause any significant change to the $\mathrm{pH}$ and color values of raw milk samples. The novel NTP system tested was able to significantly reduce $E$. coil in milk by more than a threefold $\log$ reduction without significantly affecting $\mathrm{pH}$ or color properties (Gurol et al. 2012). Some other scholars have also proved that non-thermal plasma had a significant effect in killing food microbes, such as bacterial, Saccharomyces cerevisiae, spore (Perni et al. 2008; Ermolaeva et al. 2012; Bayliss et al. 2013; Liu et al. 2013; Ma et al. 2013; Baier et al. 2013). An original non-thermal process to inactivate dehydrated 
bacterial spores has been applied (De la Noue et al. 2012). Compared with thermal processes, non-thermal plasma sterilization has significant advantages, such as at a lower temperature, short time. Meanwhile, low processing temperature retained the food nutritional content, color, flavor, and texture and maintained the freshness of products. With the loss of aroma reduced, as a result, some of the potential flavor components of juices are to be released. At same time, plasma effects on enzyme activity shows that cold plasma is capable of reducing the activity of both polyphenoloxidase (PPO) and peroxidase (POD) in the model food system. The activity of PPO was reduced by about $90 \%$ after a treatment time of $180 \mathrm{~s}$. POD was more stable and was reduced by about $85 \%$ after $240 \mathrm{~s}$ (Surowsky et al. 2013). The research has indicated that $n$-hexanal was a characteristic flavor of tomato juices (Sebastiano et al. 1995). In this paper, the volatile components of tomato juice were extracted using the simultaneous distillation apparatus from untreated and non-thermal plasma-treated tomato samples at Food Processing Laboratory in Beijing University of Agriculture in the summer of 2011. The volatile components were analyzed with the GC-MS and compared with heat-treated tomato juice. Then the changes of hexanal components in tomato juice were studied, to provide evidences for future application of the non-thermal plasma sterilization technology in tomato-processing industry.

\section{Materials and methods}

\section{Materials}

Fresh tomato: "San-Bao" variety were purchased from Beijing Xiaotangshan agronomic Park and stored below $4{ }^{\circ} \mathrm{C}$. Saturated calcium chloride, sodium hydroxide, anhydrous ether, analytical grade, were purchased from Beijing Chemical Reagent Company; Preparation of tomato juice

Raw materials $\rightarrow$ peeling $\rightarrow$ cutting $\rightarrow$ juicing

$\rightarrow$ non - thermal plasma treatment

Freshly squeezed tomato juice were filled in sterile polyethylene bottle, sealed immediately, and preserved it in a refrigerator at $4{ }^{\circ} \mathrm{C}$ for reserve.

\section{Tomato juice sterilization process}

Tomato juice was sterilized by heat sterilization $\left(85^{\circ} \mathrm{C}\right.$ for $30 \mathrm{~min}$ ) or by equipment shown in Fig. 1, which could produce electric plasma at high-voltage power supply $\left(10 \mathrm{kV}\right.$ at $30{ }^{\circ} \mathrm{C}$ for $\left.5 \mathrm{~min}\right)$.
Non-thermal plasma equipment was supplied by Nanjing Suman Electronics Corporation; Agilent 6890 N GCMS, USA, with G1701MSD ChemStation and NIST02 standard library; Simultaneous distillation device was purchased from Beijing Glass Instrument Factory. Selfmade liquid plasma sterilization tube, as shown in Fig. 1. Tomato juice was pumped into apparatus through inlet 7 by a peristaltic pump. When it passed through bubbling device 6 , it was mixed with the air to form homogeneous bubbles. Currents were produced by NTP supply and passed to inner electrode 3. Electric discharge was produced between inner electrode 3 and ground electrode tube 5; meanwhile, reactive free radicals were produced. The microbes in tomato juice were inactivated by reactive free radicals in the chamber. Then sterilized juice overflowed from outlet. The components of treated juice were analyzed.

\section{Simultaneous distillation-extraction}

Take $200 \mathrm{~mL}$ of tomato juice sample in a $250-\mathrm{mL}$ roundbottomed flask and weighed $40 \mathrm{~mL}$ of the distilled diethyl ether in a $100-\mathrm{mL}$ round-bottomed flask; simultaneous distillation-extraction for $2 \mathrm{~h}$ is carried out, and stop heating until it cools down. Add a small amount of anhydrous sodium sulfate (about $2-3 \mathrm{~g}$ ) in a $100-\mathrm{mL}$ flask and dry it for $2 \mathrm{~h}$ to remove water. After pouring into $80-\mathrm{mL}$ concentrate bottle, the dried sample then was incubated in water bath at $40{ }^{\circ} \mathrm{C}$. It was carefully concentrated to

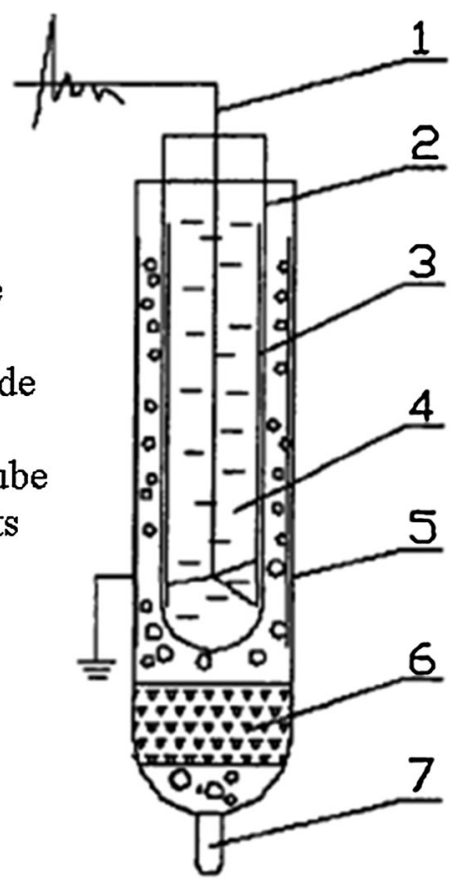

Fig. 1 Schematic of experimental layout 


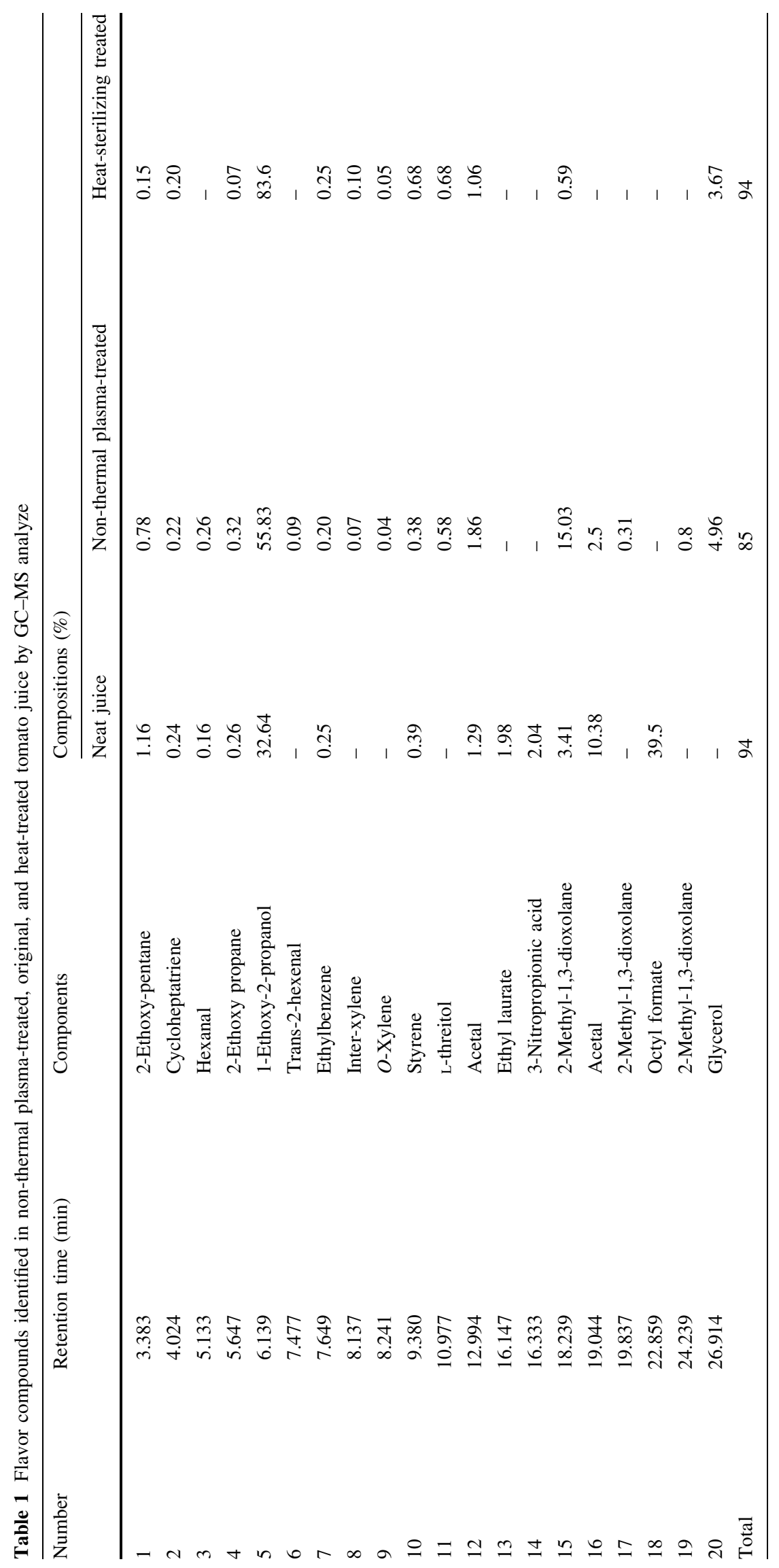



chromatogram of GC-MS of tomato juice
Fig. 2 Total ion current
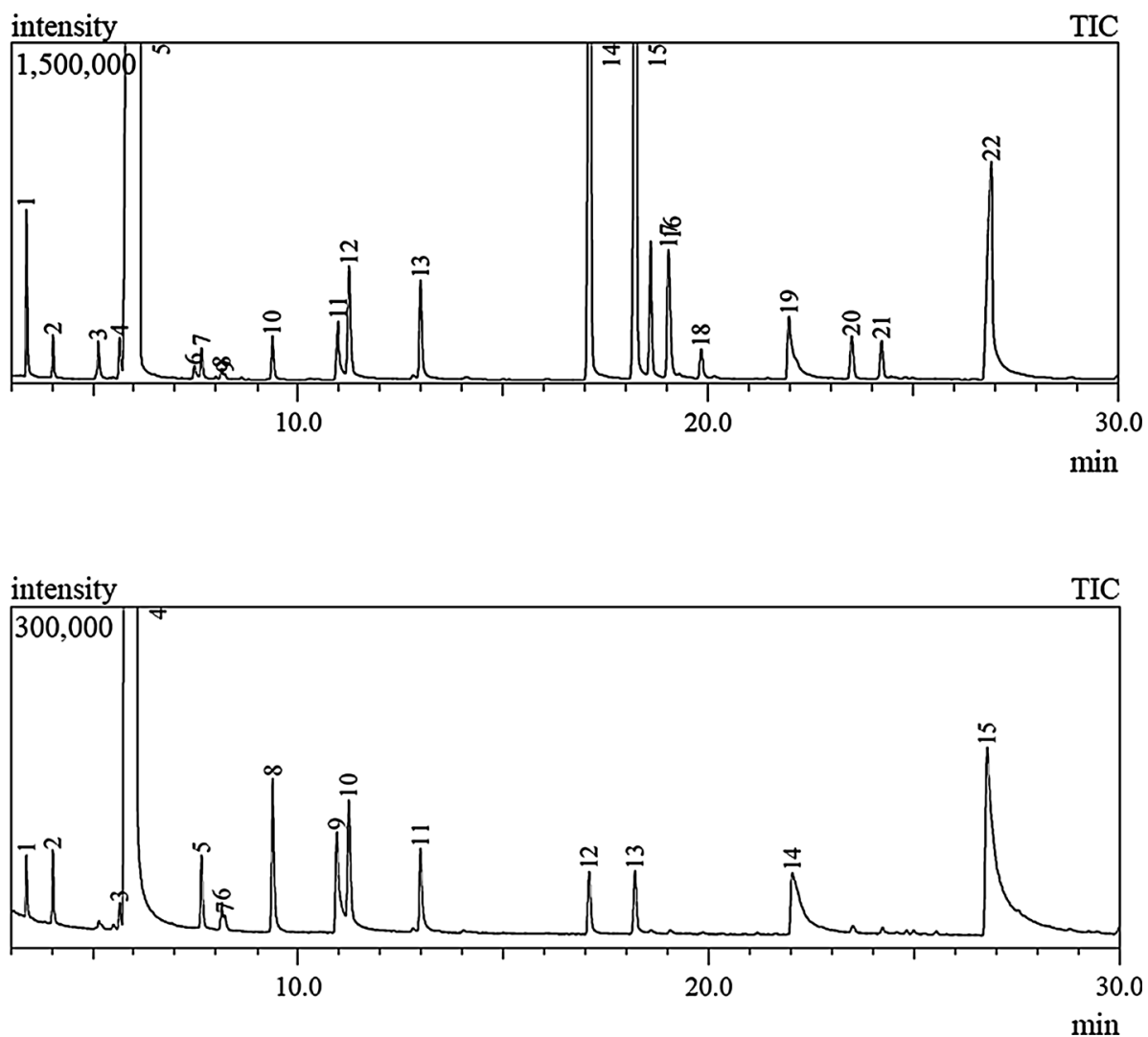

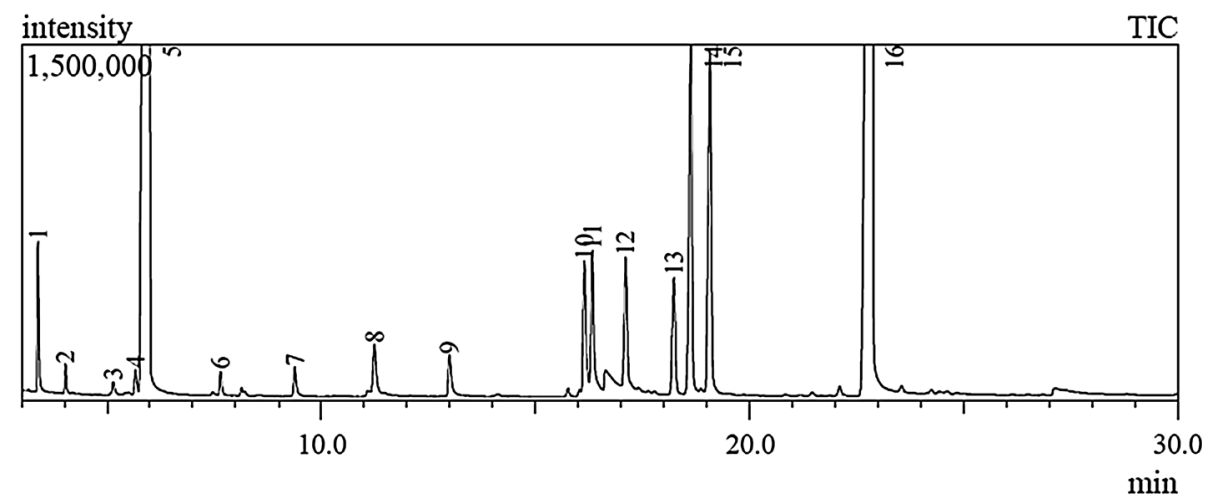

Fig. 3 Total ion current chromatogram of GC-MS of non-thermal plasma-treated tomato juice
Fig. 4 Total ion current chromatogram of GC-MS of heat treatment tomato juice
$2.0 \mathrm{~mL}$ by Vigreaux column, and then $1 \mu \mathrm{L}$ was taken for GC-MS analysis (Tian et al. 2009).

\section{GC-MS analysis}

Chromatographic conditions: HP-5 capillary column $(30 \mathrm{~m} \times 0.25 \mathrm{~mm} \times 0.25 \mu \mathrm{m}), \quad 50{ }^{\circ} \mathrm{C}$ as the starting temperature and maintained for $2 \mathrm{~min}$, heated to $110^{\circ} \mathrm{C}$ with the rate of $8{ }^{\circ} \mathrm{C} / \mathrm{min}$, and then raised to $220{ }^{\circ} \mathrm{C}\left(6^{\circ} \mathrm{C} /\right.$ min), and finally raised to $240{ }^{\circ} \mathrm{C}\left(10{ }^{\circ} \mathrm{C} / \mathrm{min}\right)$, maintained for $1 \mathrm{~min}$; inlet temperature is $250{ }^{\circ} \mathrm{C}$; injection volume $1 \mu \mathrm{L}$; split ratio $5: 1$, solvent delay of $3 \mathrm{~min}$. MS conditions: ion source temperature of $250{ }^{\circ} \mathrm{C}$; transfer line temperature of $250{ }^{\circ} \mathrm{C}$; EI as the ionization mode, emission current $200 \mu \mathrm{A}$; electron energy of $70 \mathrm{eV}$; scanning the mass range of 50-650 amu.

\section{Results and discussion}

After the GC-MS separation and identification, 16 kinds of ingredients were isolated from un-treated tomato juice, accounting for $94 \%$ of the total mass fraction; 20 kinds of ingredients of tomato juice were isolated from non-thermal 
plasma sterilization treatment, accounting for $85 \%$ of the total mass fraction. Fifteen kinds of components were isolated from thermal sterilization, representing $94 \%$ of the total mass fraction, as shown in Table 1 . These volatile components mainly composed of hydrocarbons, esters, alcohols, aldehydes, acids, and other substances. From Table 1, it can be seen that after the non-thermal plasma treatment, trans-2-hexenal, m-xylene, $o$-xylene, L-threitol, and glycerol of tomato juice are increased, and lauryl ethyl 3-NPA reduced. From chromatogram, the content of key mediate of hexanal (with the retention time of $5.133 \mathrm{~min}$ ) in neat juice was 1.6 times less than that in nonthermal plasma treated juice (Figs. 2, 3). However, hexanal components were totally disappeared after heat treatment (Fig. 4). This showed that non-thermal plasma treatment has a certain effect on the volatile components of tomato juice. A larger proportion of volatile components of tomato juice, 1-ethoxy-2-propanol, increased $71.8 \%$ after nonthermal plasma treatment, while increased $256.4 \%$ with heat sterilization, indicating that after heat sterilization treatment, the evaporation composition of tomato juice changed significantly higher than non-thermal plasma treatment. Meanwhile, non-thermal plasma treatment has less effect on volatile chemical components of tomato juice. Compared with ultra-high-pressure processing (HHP) (Butz et al. 2003; Boulekou et al. 2011; Augusto et al. 2013), non-thermal plasmas are emerging and promising technologies for sanitation because they are both efficient and cheap (Moreau et al. 2008).

Volatile components in tomato juice were determined by GC-MS. The effects of different treatments were analyzed. The main results indicated as follows: five new substances were produced by non-thermal plasma-treated tomato juice, such as anti-2-hexene aldehyde, and two substances were lost, such as ethyl laurate. The hexanal content of non-thermal plasma-treated tomato juice had increased by 1.6 times. Non-thermal plasma treatment had no significant effect on the smell of tomato juice, but the change of heat sterilization was significantly higher than that of nonthermal plasma treatment.

\section{Conclusion}

The effect of non-thermal plasma sterilization technology for fruit and vegetable juice beverage flavor was first studied. The NTP treatments were simple and quick and have less impact on flavor and aroma of tested samples by the analysis data. Bacteria can be killed and residues can be cleared away through the gas circulation system. The produced plasma is limited within a containment system, causing no harm to the operator. The advantages of NTP technology are time saving, low operating temperature, and keeping fruit fresh. The technology can be widely used in a variety of fruits for sterilization. Non-thermal plasma sterilization technology can keep the original flavor and nutrients of food and is expected to replace existing thermal pasteurization food processes.

Acknowledgments This work was supported by Shenzhen Science and Technology Project (Fund No. JC200903180677A),and General Administration of Quality Supervision, Inspection and Quarantine (AQSIQ) Science Project (Fund No. 2013IK052), China.

\section{References}

Augusto PED, Ibarz A, Cristianini M (2013) Effect of high pressure homogenization $(\mathrm{HPH})$ on the rheological properties of tomato juice: viscoelastic properties and the Cox-Merz rule. J Food Eng 114:57-63

Baier M, Foerster J, Schnabel U (2013) Direct non-thermal plasma treatment for the sanitation of fresh corn salad leaves: evaluation of physical and physiological effects and antimicrobial efficacy. Postharvest Biol Technol 84:81-87

Bayliss DL, Shama G, Kong MG (2013) Restoration of antibiotic sensitivity in meticillin-resistant Staphylococcus aureus following treatment with a non-thermal atmospheric gas plasma. Int $\mathbf{J}$ Antimicrob Agents 41:398-399

Boulekou S, Mallidis C, Taoukis PS, Stoforos NG (2011) Quality evaluation of slightly concentrated tomato juice produced under high pressure conditions. 11th international congress on engineering and food (ICEF11). Procedia Food Sci 1:800-804

Butz P, Fernandez Garcia A, Lindauer R, Dieterich S, Bognar A, Tauscher B (2003) Influence of ultra-high pressure processing on fruit and vegetable products. J Food Eng 56:233-236

De la Noue AC, Espinasse V, Perrier-Cornet JM, Gervais P (2012) High gas pressure: an innovative method for the inactivation of dried bacterial spores. Biotechnol Bioeng 109:1996-2004

Deng SR, Ruan CY, Mok G (2007) Inactivation of Escherichia coli on almonds using nonthermal plasma. J Food Sci 72:62-66

Ermolaeva SA, Sysolyatina EV, Kolkova NI, Bortsov P, Tuhvatulin AI, Vasiliev MM, Mukhachev AY, Petrov OF, Tetsuji S, Naroditsky BS, Morfill GE, Fortov VE, Grigoriev AI, Zigangirova NA, Gintsburg AL (2012) Non-thermal argon plasma is bactericidal for the intracellular bacterial pathogen Chlamydia trachomatis. J Med Microbiol 61:793-799

Gurol C, Ekinci FY, Aslan N, Korachi M (2012) Low temperature plasma for decontamination of $E$. coli in milk. Int $\mathrm{J}$ Food Microbiol 157:1-5

Hayase F, Chung TY, Kato H (1984) Changes of volatile components of tomato fruits during ripening. Food Chem 14:113-124

Lin XY, Ruan RS, Zhu RB (2006) Study on a new non-thermal pasteurization technique for liquid foods. Food Sci 27:57-61

Liu XH, Hong F, Guo Y, Zhang J, Shi JJ (2013) Sterilization of Staphylococcus Aureus by an atmospheric non-thermal plasma jet. Plasma Sci Technol 15:439-442

Ma HB, Ruan R, Lin XY (2002) Non-thermal pasteurization of liquid foods using non-thermal plasma. Trans CSAE 18:155-159

Ma RN, Feng HQ, Liang YD (2013) An atmospheric-pressure cold plasma leads to apoptosis in Saccharomyces cerevisiae by accumulating intracellular reactive oxygen species and calcium. J Phys D Appl Phys 46:85401-85429

Moreau M, Orange N, Feuilloley MGJ (2008) Non-thermal plasma technologies: new tools for bio-decontamination. Biotechnol Adv 26:610-617 
Perni S, Liu DW, Shama G (2008) Cold atmospheric plasma decontamination of the pericarps of fruit. $\mathrm{J}$ Food Prot 71:302-308

Riu-Aumatella M, Castellar M, Lopez-Tamames E, Galassi S, Buxaderas S (2004) Characterization of volatile compounds of fruit juices and nectars by HS/SPME and GC/MS. Food Chem 87:627-637

Salles S, Nicklaus, Septier C (2003) Determination and gustatory properties of taste-active compounds in tomato juice. Food Chem 81:395-402

Sebastiano P, Alessandra B, Claudio G, Enzo V (1995) Effects of ultra-high hydrostatic pressure treatments on the quality of tomato juice. Food Chem 52:35-41
Servili M, Selvaggini R, Taticchi A, Begliomini AL, Montedoro GF (2000) Relationships between the volatile compounds evaluated by solid phase microextraction and the thermal treatment of tomato juice: optimization of the blanching parameters. Food Chem 71:407-415

Surowsky B, Fischer A, Schlueter O, Knorr D (2013) Cold plasma effects on enzyme activity in a model food system. Innov Food Sci Emerg Technol 19:146-152

Tian HX, Yi YJ, Zheng XP (2009) Analysis of volatile flavor compounds in homemade cheese with the use of simultaneous distillation extraction and gas chromatography-mass spectrometry. Food Ferment Ind 53(11):143-146 